\title{
Assessment of climate change impacts on environmental sustainability in Afghanistan
}

\author{
Ahmad Tamim Mehrad* \\ People's Friendship University of Russia (RUDN University), Miklukho-Maklaya 6, 117198 \\ Moscow, Russia
}

\begin{abstract}
Climate change is a global phenomenon that became one of the most predominant environmental challenges facing our world today. Natural events and anthropogenic activities are responsible for increasing the negative impacts and risks associated with climate change. Developing countries in Asia and Africa are bearing much of the climate change burden due to rapid population growth, crop failures, and lack of required technological and financial resources to mitigate the risks. Afghanistan, like other developing countries, is highly vulnerable to the severe impacts of climate change. In Afghanistan, climate change is related to various adverse effects on water resources, agriculture, forests, biodiversity, increasing temperature, and changing the environmental landscape. This paper analyses the impact of climate change on environmental sustainability in Afghanistan.
\end{abstract}

\section{Introduction}

Afghanistan is a highland and landlocked country, has an area of $652,000 \mathrm{~km}^{2}$, and is located in the crossroad ofCentral and SouthAsiabetween $29^{\circ} 35-38^{\circ} 40^{\prime}$ latitudeand $60^{\circ} 31^{\prime}-74^{\circ} 55^{\prime}$ of longitude.Itisbounded in the northby Uzbekistan, Tajikistan, and Turkmenistan, northeastwithChina, in the southandeastwith Pakistan, andwith Iran in the west. Mountains and plateaus occupy $82 \%$ of Afghanistan territory, whereas the rocky deserts and dry steppes constitute the dominant ecosystems[1].

Approximately $1.8 \%$ of the country's territory is covered by forests, with about $12 \%$ of arable land [2]. Currently, Afghanistan is suffering from severe drought and frequent floods. Most of the southern, eastern, and central territories of the country have low precipitation, and therefore suffering from severe droughts.[3] On the other hand, northern and northwestern provinces are vulnerable to seasonal floods. [4]

Afghanistan has a continental arid and semi-arid climate, with cold winters and hot summers. The temperature, rainfall, and snow vary widely across the country. The highest temperature can rise to $50^{\circ} \mathrm{C}$ in summer, and -20 in winter, with maximum precipitation, occurs in winter and spring (except for the southeastern parts) [5].

\footnotetext{
${ }^{*}$ Corresponding author: ahmadtam32@gmail.com
} 


\section{Methods}

The research is designed based on analyzing the climatic data and the environmental sustainability index of the assigned components (water resources, agriculture, biodiversity, and forests). For analyzing the temperature and precipitation, one of the assigned models by the World bank (Ensemble) under the scenarios of RCP 8.5 (High emission) and RCP 2.6 ( Low emission), has been used. In order to evaluate the climate change impacts on the environment, the vulnerability index has been applied.

\section{Climate Change Context}

Since 1960, arid and semi-arid countries, such as Afghanistan, have experienced severe climate change impact, resulting in an extensive expansion of drylands, droughts, and agricultural vulnerability [6,7]. Afghanistan's mean annual temperature has risen by $1.8^{0} \mathrm{C}$ since 1950, with the highest temperature increase in Southern Plateau $\left(2.4^{\circ} \mathrm{C}\right)$, followed by the Northern region $\left(1.7^{\circ} \mathrm{C}\right)$, the Central Highlands, and the Hindu Kush Mountains, $\left(1.6^{\circ} \mathrm{C}\right)$, and the Eastern region $0.7^{\circ} \mathrm{C}$.

Analyzing precipitation trends in Afghanistan from 1950 to 2019 indicates that heavy precipitation mostly occurs in the spring and winter seasons. The January, February, and March months have the highest rainfall, while September and July have the lowest. At the same time, in the spring, precipitation has significantly decreased by $32 \%$, but it remained unchanged in the winter. Since 1950, rainfall has substantially fallen in Afghanistan, and this trend is likely to continue in the future.

\subsection{Climate Projection}

The extent of climate change impact depends on increasing greenhouse gases emission and aerosols and the vulnerability of the climate system to those emissions[8]. Preliminary, regional, and local climate change scenarios are necessary for analyzing the impact of climate change [9]. Decreasing precipitation and increasing temperature are the two clear signals of climate change impacts in Afghanistan.

\subsection{Temperature}

Current trends indicate that under RCP 8.5 (High emission Scenario), Afghanistan's mean temperatures will continue to rise between $1.5^{\circ} \mathrm{C}$ to $3^{\circ} \mathrm{C}$ until the $2050 \mathrm{~s}$, and between $2.2^{\circ} \mathrm{C}$ to $6.3^{\circ} \mathrm{C}$ by $2100 \mathrm{~s}$. An optimistic scenario RCP 2.6 (Low emission) suggests a $1.5^{\circ} \mathrm{C}$ increase until the $2050 \mathrm{~s}$ and $2.5^{\circ} \mathrm{C}$ by the $2100 \mathrm{~s}$. Actualization or fluctuations in both scenarios are dependent on global emission scenarios. Under both scenarios, substantial warming is expected all over the country, with the most severe temperature increase in the north (Northern plains), the Hindu Kush, and Central Highlands Fig 1. 

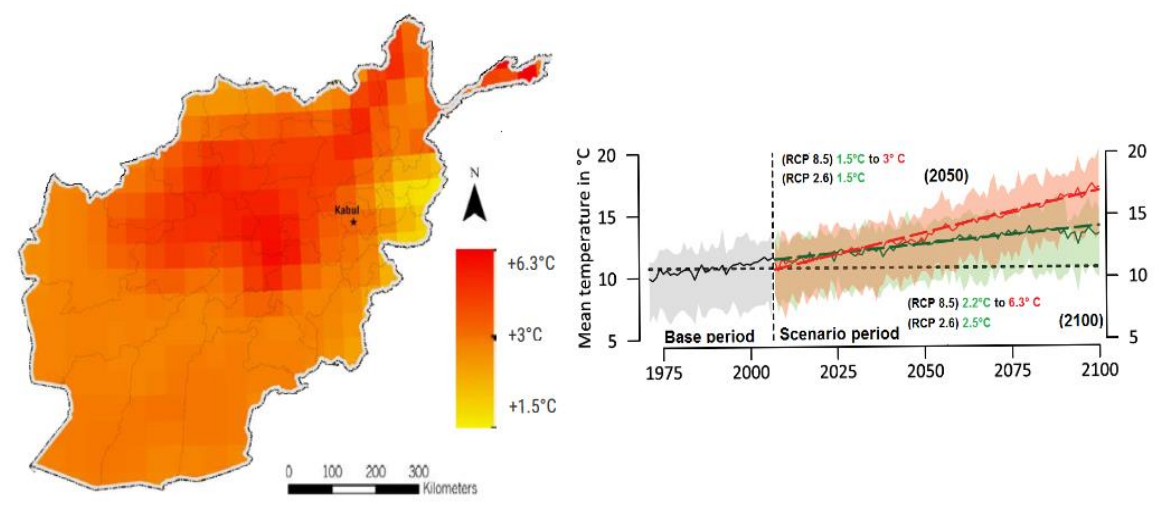

Fig 1. Depicts the projected increase in temperature of different regions of Afghanistan

\subsection{Precipitation}

There are different levels of uncertainties in the assessment of climate change trends due to difficulties in projecting related climatic components such as precipitation [9]. The annual precipitation in Afghanistan is expected to have high variability across the country, with a slight decrease of approximately 12 to $25 \mathrm{~mm}$ by $2050 \mathrm{~s}$, and 15 to $50 \mathrm{~mm}$ by 2100 . The rainfall projects to decrease in spring except in some areas of the northern and southeast regions. The winter has become drier in the past five decades due to high evaporation, and the trend is expected to continue. Pamir and Wakhan glaciers, that are the source of northern Afghanistan rivers, experienced a shrinkage level of up to $18 \%$ by 2019 and is expected to be shrunk by about $15.9 \%$ in 2050 and $27.3 \%$ in 2100 respectively. Under the available optimistic scenario, there will be a precipitation increase of about $30-40 \mathrm{~mm}$ in the southern and the northeastern (Hindu Kush ) regions.
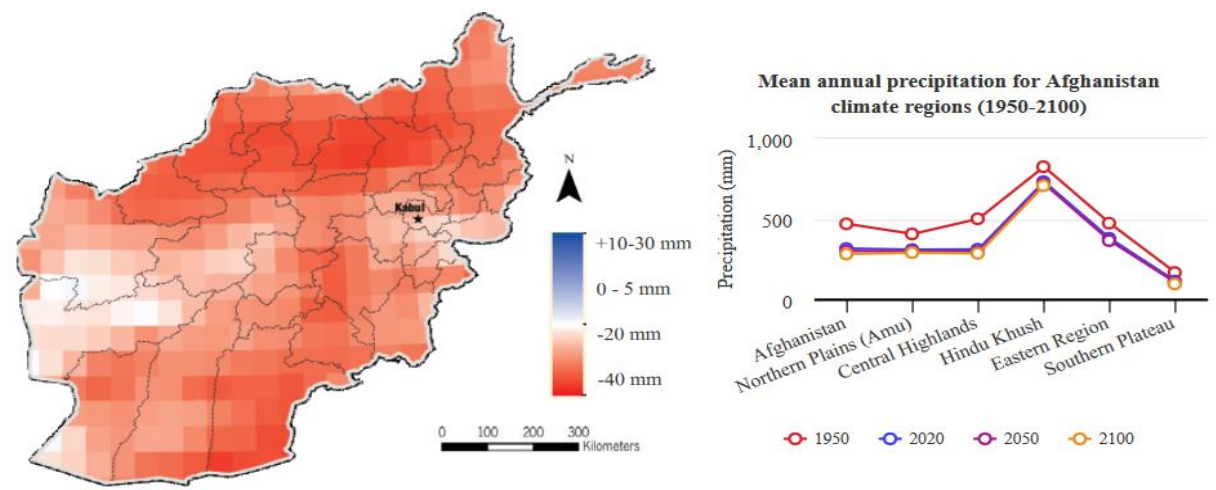

Fig.2.Project the change in Afghanistan precipitation patternunder different scenarios

\section{Climate change and environmental sustainability}

Changing climatic patterns is continued to negatively impact environmental sustainability in Afghanistan, by putting pressure on water resources, agriculture, forests, biodiversity, etc. 


\subsection{Water Resources}

Water resources have been sensitive to different variations in climatic patterns. The changes in theamount and quality of the water resources in Afghanistan are mostly connected with the impacts of climate change. In Afghanistan, the water supply for drinking, irrigation, and maintenance of wetlandecosystems is carried by five river basins, wells, and traditional reservoirs. These water basins are mostly fed by the seasonal melting of snow in Pamir, Hindu Kush, and Baba mountains and rainfall [10]. The decrease inthe water level and intense droughts in the level basins, reservoirs, and groundwater systems hadthreatened the sustainable water supply of communities in Afghanistan, leading to various crises, including lack of access to water, diseases, conflict, and population displacement. In addition, rapid snow and glacier melting has led to the frequent flood, killing many inhabitants and deteriorating the environmental condition [11]. Increasing climate impacts would lead to more droughts and water scarcity in Afghanistan.

\subsection{Agriculture}

Agriculture is the most vital part of Afghanistan's economy, as nearly $80 \%$ of the country's population is engaged in this sector [12]. Roughly, 26\% of Afghanistan's gross domestic income comes from agricultural products [13]. After the water resources, agriculture is the second most vulnerable sector against climate change impacts. The factors such as reduced river flow, increasing soil evaporation, and less rainfall during the cultivation seasons have drastically affected agricultural productivity and crop choice availability in Afghanistan. Due to rising temperatures and changes in rainfall patterns, vegetation, and crop yields have significantly decreased, especially in the west and southwest areas of the country, leading to population displacement and increasing poverty [14]. Reducing rainfall in the northern regions has affected water supply for rice cultivation, and therefore, the continuation of this trend will reduce rice production in Afghanistan.

The temperaturefluctuationduring the winterwill likely increaseweeds, pests,andplantdiseases, therebyincreasing the costofproduction, usingmoretoxinsandpesticides, andpolluting the environment. Falling rainfall in most parts of Afghanistan has reduced the quantitative and qualitative capacities of pastures and livestock production.

\subsection{Forest and Rangelands}

The environmental value of forests and grasslands is more important than their economic value, as they are very vital for ensuring a sustainable life cycle. Forests occupy about 1.1 million hectares or just $1.6 \%$ of the Afghanistan territory [15]. Roughly $68 \%$ of the country's forests have disappeared due to decades of war, deforestation, and forest fires. The area of grasslands in the country is currently 31 million hectares and, the share of pastures in the total area is $49 \%$ [1]Decreasing in rainfall had significant effects on eastern, western, and northern forests, especially on forest species of Badghis, Balkh, and Samangan provinces. Due to the variations inprecipitation and torrential rains in pastures, soil erosion increased and aggravated the fertility of the pasture. Increasing overgrazing, and converting wetlands to agricultural land has led to extensive degradation and reducing land productivity.

Some forest trees have not been able to achieve proper longitudinal and volumetric growth due to heat and humidity. The influx of pests and diseases is also one of the influential events that have occurred due to climate change in Afghanistan forests. 


\subsection{Biodiversity}

The diversity of living species is very crucial for measuring the environmental sustainability of Afghanistan. Biodiversity is not only ensuring environmental stability but also provideimmense economic benefits. Afghanistan is home to a variety of more than 700 species of birds, mammals, amphibians, reptiles, butterflies, fishes, and 3,500-4,000 native vascular plant species. [16] During the last five decades, climate change posed different threats to biodiversity and led to its declination. The five permanent and seasonal river basins of Afghanistan are home to a variety of animal and plant species. But, they have lost nearly $24 \%$ of their biodiversity in the past 30 years [17].

Decreasing rainfall and rising temperatures in most of the northern, northeastern, and central zones of Afghanistan have caused a significant water shortage for most mammals and birds species living in these zones and led to their migration to protected areas, such as Wakhan National Park in Tajikistan and China. The lack of water resources in HamounSistan, Puzak, and Saberi, destroyed the ecosystem and led to the mortality of more than 413 species and migration of bird populations [18]. The future climate trends suggest that animal species, especially snow leopards and deer, will be at high risk of extinction due to climate change.

\section{Environmental Sustainability}

The multi-functional analyses of an environmental vulnerability index for the water resources, agriculture, forest and rangelands, and biodiversity of Afghanistan indicates that most of these sectors and their sub-parts are very far from the ideal environmental sustainability level.

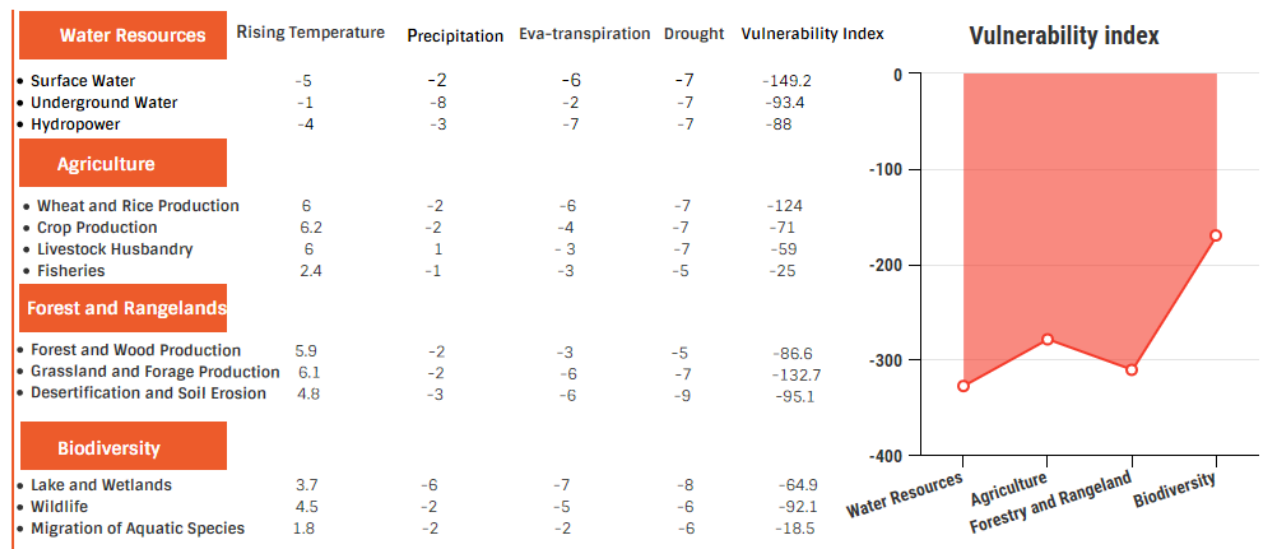

Fig.3.The environmental vulnerability index of Afghanistan

\section{Conclusion}

Afghanistan is one of the most vulnerable countries against climate change impacts. Climate change has led to disastrous droughts, frequent floods, water shortages, and an overall negative environmental sustainability balance. The countryhas experienced severe climatic variations in the past decades and, it is expected to face even more challenges in the future. The temperature is projected to rise exponentially, and the rainfall will have a slight decrease. This trend indicates that climate changewill cause more extensive and 
significant damage to water resources, agriculture, environment, biodiversity, and other sectors.

In such circumstances, mitigating and managing the consequences of climate change can reduce theimpacts to some extent and prevent the destruction of production capacity.Therefore, changing and modifying the production pattern of agricultural products based on less water consumption, using more renewable energy, realizing climate change as a critical phenomenon, and adopting effective policies will lead to sustainability.

\section{References}

1. M. Z. Taniwal, Maiwand Press, Kabul, 18 (2008)

2. FAO, The Islamic Republic of Afghanistan,Land Cover Atlas(2016)

3. RCRC, Emergency AppealAfghanistan: Drought and flash Floods (2020)

4. L. Safi. Carrying Capacity and Natural Risk Evaluation in Northern Afghanistan, KBU, 4, 29(2009)

5. G. J. Arez, Kabul University Press, 48 (2007)

6. J. Huang, M. Ji, Y. Xie, S. Wang, Y. He. J. Ran, ClimDyn.,46, 1131 (2016)

7. B. Ababaei, H. R. Etedali, TheorApplClimatol.,137, 2977-2992 (2019)

8. K Hayhoe et al., Climate Science Special, I (2017)

9. Timon. Olsson et al., Earth Syst. Sci., 19, 3217(2015)

10. A T Mehrad, TRU, 95-110 (2018)

11. A.B. Qureshi.Emergency and disaster reports, 28 (2014)

12. Afghanistan Agricultural Sector Review Revitalizing, Agriculture for Economic Growth, Job Creation and Food Security (2014)

13. Afghanistan Ministry of Agriculture and Livestock, yearly report (2018)

14. NEPA \& UNEP,National Capacity Needs Self-assessment for Global Environmental(2019)

15. Global forest resources assessment,Country profile; Afghanistan (2014)

16. CBD. Climate Change and Biodiversity (2017)

17. S. Omar, K. Jamil. The Historical Biodiversity Assessment of Afghanistan, KU, 3 (2013)

18. H. Kamiabinia, F. Aslani. The Hamoun and Sistan Forgotten Ecosystems, 45, (2017) 